\title{
Characteristics of GaN Thin Films Using Magnetron Sputtering System
}

\author{
Hasina F. Huq, Rocio Y. Garza, Roman Garcia-Perez \\ Electrical Engineering, University of Texas Pan American, Edinburg, USA \\ Email: hasina.huq@utrgv.edu,rygm00@yahoo.com,roman.garcia01@utrgv.edu
}

How to cite this paper: Huq, H.F., Garza, R.Y. and Garcia-Perez, R. (2016) Characteristics of GaN Thin Films Using Magnetron Sputtering System. Journal of Modern Physics, 7, 2028-2037.

http://dx.doi.org/10.4236/jmp.2016.715178

Received: January 23, 2016

Accepted: November 6, 2016

Published: November 9, 2016

Copyright $\odot 2016$ by authors and Scientific Research Publishing Inc. This work is licensed under the Creative Commons Attribution International License (CC BY 4.0).

http://creativecommons.org/licenses/by/4.0/

\begin{abstract}
The paper presents a polycrystalline $\mathrm{GaN}$ thin film with a hexagonal wurtzite structure under the optimized sputtering conditions of $40 \mathrm{~W}$ RF power, $5 \mathrm{mT}$ working pressure, using pure nitrogen gas with a substrate temperature of $700^{\circ} \mathrm{C}$. The study examines the effects of surface disorders and incorporates it in the thin films characteristics. A radio frequency (RF) Ultra High Vacuum (UHV) Magnetron Sputtering System has been used for the deposition of Gallium Nitride ( $\mathrm{GaN})$ on silicon, sapphire and glass substrates with different parameters. The power is varied from $40 \mathrm{~W}$ to $50 \mathrm{~W}$, and the pressure from $4 \mathrm{mT}$ to $15 \mathrm{mT}$. The effects of the RF sputtering powers and gas pressures on the structural properties are investigated experimentally. Sputtering at a lower RF power of $15 \mathrm{~W}$ does increase the $\mathrm{N}$ atomic percentage, however the deposition rate is substantially slower and the films are amorphous. GaN deposited on both silicon and sapphire wafer resulted in thin films close to stoichiometric once the $\mathrm{N}_{2}$ concentration is $60 \%$ or higher. It is also observed that the substrate cooling/heating effects improve the quality of the thin films with fewer defects present at the surface of the GaN epi-structure.
\end{abstract}

\section{Keywords}

GaN, UHV Magnetron Sputtering, RF Power, HEMT, Thin Film Characterization

\section{Introduction}

The need for concise and accurate growth of GaN thin films on a specific substrate with a specific doping is greatly emerging for the biosensor applications [1] [2]. Surfaces and interfaces are an integral part of GaN High Electron Mobility Transistors (HEMTs). Disorders on the interfacial planes are quite important in GaN HEMTs. The effects of spontaneous and piezoelectric polarization induced charges at the AlGaN/GaN heterointerface also play an important role in the characterization of HEMT devices for 
biosensor application.

In addition, GaN HEMTs also have a high resistance to chemical corrosion by acids, have non-toxicity to living cells, allow extreme sensing environments, and are chemically inert [3] [4], making them suitable biosensors. Early research has shown great potential for AlGaN/GaN HEMTs as biosensors where silicon ( $\mathrm{Si}$ )-based Field Effect Transistors (FETs) have been ineffective [5].

Although GaN HEMTs have shown to be suitable transistors, they have not been popularized due to fabrication issues. Growing high quality $\mathrm{GaN}$ has been a main challenge as this material does not exist purely in nature [6] [7]. Most of the fabrication processes are not suitable for sensitive electronic applications as they are complex, involve corrosive materials, and require high temperature depositions [8]. In the present work, we extend the research by investigating optimized sputtering conditions of GaN and $\mathrm{AlGaN}$, for the purpose of preparing an AlGaN/GaN heterostructure by $\mathrm{RF}$ magnetron sputter technique. This leads to the fabrication of an AlGaN/GaN HEMT biosensor (Figure 1).

\section{Methodology}

The sputter grown GaN thin films are preferred because of the ease of operation, thickness control, low temperature deposition, sequential deposition of different films, and less toxicity [9]. Although sputtering of GaN has not yet been fully explored, sputtering of $\mathrm{GaN}$ has achieved polycrystalline and single crystal $\mathrm{GaN}$ by sputtering of a GaN target [10] [11] [12] [13] [14], a gallium (Ga) target [15] [16] [17], and GaN powder target [18] [19] [20].

Utilizing an Ultra High Vacuum (UHV) Magnetron Sputtering System, GaN films have been deposited by radio-frequency (RF, $13.5 \mathrm{MHz}$ ) magnetron sputtering with a $\mathrm{GaN}$ target. Four sets of $\mathrm{GaN}$ thin films are deposited on silicon, sapphire and glass substrates. The first set of sample is deposited in Ar gas; the second set of sample is deposited in mixed Ar and $\mathrm{N}_{2}$ gas (where the ratio of Ar is higher than $\mathrm{N}_{2}$ ); the third set of sample is deposited in mixed $\mathrm{N}_{2}$ and Ar gas (where the ratio of $\mathrm{N}_{2}$ is higher than Ar); the fourth set of sample is deposited in $\mathrm{N}_{2}$ gas. Finally, substrate heating is used to reduce incorporation of oxygen impurities during the deposition process. The base pressure is below $3 \times 10^{-6}$ Torr, and the working pressure for all synthesis is above $3 \times 10^{-3}$ Torr. Prior to sputtering, a pre-sputtering process is performed for more than $30 \mathrm{~min}$

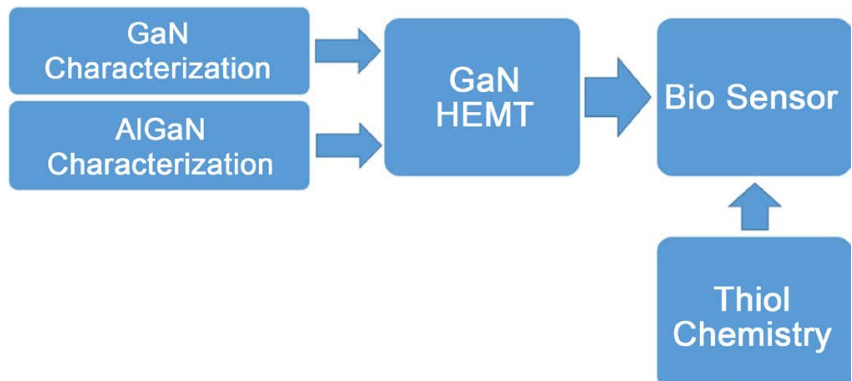

Figure 1. Overall research outline. 
to eliminate any contaminants from the target. Sputtering is then conducted with varying RF power of $\mathrm{GaN}$ target from $15 \mathrm{~W}$ to $50 \mathrm{~W}$. The substrate temperature is varied from $25^{\circ} \mathrm{C}$ to $700^{\circ} \mathrm{C}$. Substrates are rotated at $30-60 \mathrm{RPM}$ during deposition to enhance film uniformity. Imaging tools such as the Atomic Force Microscopy (AFM), Scanning Electron Microscopy (SEM), Energy-dispersive X-ray spectroscopy (EDAX), $\mathrm{X}$-ray Diffractometer (XRD), and X-ray photoelectron spectroscopy (XPS) are used to characterize each sample.

\section{Results}

GaN thin films samples are made using the magnetron sputtering system under various conditions. Sputtering with pure argon gas under $40 \mathrm{~W}-50 \mathrm{~W}$ RF power and low pressure $(4 \mathrm{mT}-5 \mathrm{mT}$ ) has resulted in dark shade films that are highly nitrogen $(\mathrm{N})$ deficient with an average ratio of $0.16 \mathrm{~N} / \mathrm{Ga}$ for all four samples. Table 1 shows the characteristics of sputtering method using pure argon gas. The darker shades are attributed to high concentrations of $\mathrm{Ga}$, as is discussed in [18]. EDS spectrum revealed impurities of oxygen $(\mathrm{O})$ and carbon $(\mathrm{C})$, which are attributed to impurities. Further XPS analysis indicated that $\mathrm{C}$ is only found at the surface of the thin films (Figure 2).

The effects of various concentrations of sputtering gas on the deposition resulted in

Table 1. Characteristics of sputtering using pure argon gas.

\begin{tabular}{cccccccc}
\hline \multicolumn{8}{c}{ Pure Argon Gas } \\
\hline Power (W) & Pressure (mT) & Thickness (nm) & Ga \% & N \% & O \% & N/Ga Ratio & Time (hr.) \\
\hline 40 & 4 & 175 & 30.11 & 4.87 & 26.22 & 0.16 & 1 \\
40 & 5 & 165 & 28.25 & 5.48 & 22.04 & 0.19 & 1 \\
50 & 4 & 198 & 38.63 & 6.19 & 28.45 & 0.16 & 1 \\
50 & 5 & 185 & 30.97 & 4.05 & 33.09 & 0.13 & 1 \\
\hline
\end{tabular}

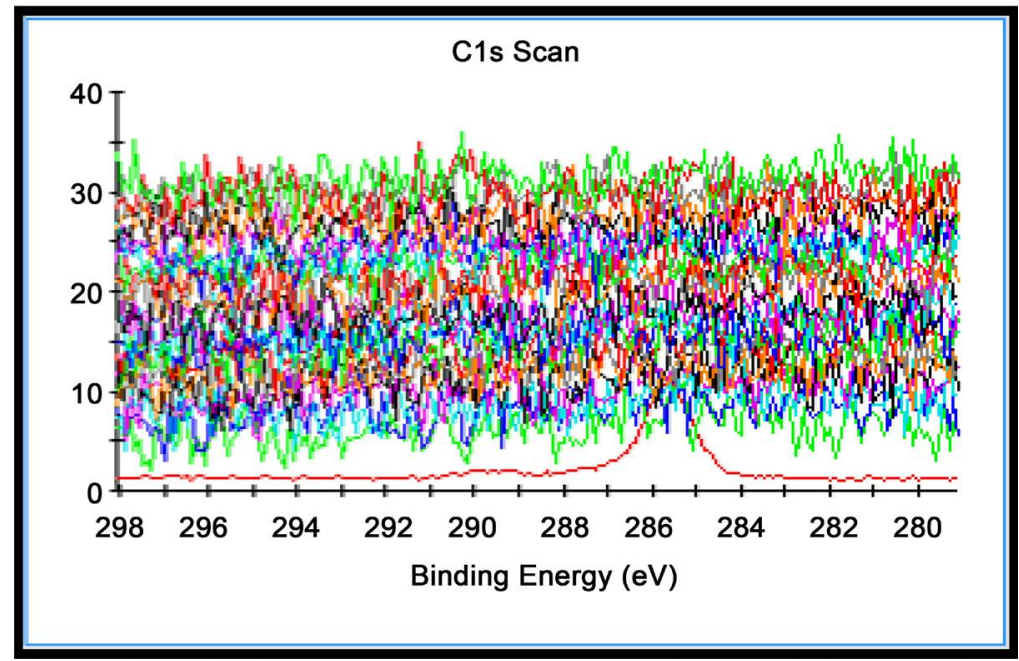

Figure 2. X-ray photoelectron spectra depicting the carbon within the sputtered films (in the surface layer). 
an improvement on the $\mathrm{N} / \mathrm{Ga}$ ratio as well as reduced target poisoning as the sputtering gas has a higher concentration (60\% or higher) of $\mathrm{N}_{2}$. Table 2 shows the different characteristics of each film. The experimental results show that the optimized sputtering power is $40 \mathrm{~W}$ RF power. When sputtering with $50 \mathrm{~W}$ RF power, target poisoning is observed at low pressures. To reduce the effect of target poisoning, higher pressures (20 $\mathrm{mT}-30 \mathrm{mT}$ ) have to be used. However, at these pressures, there is still a lack of $\mathrm{N}$ in the film. The deposition rate is substantially slower and the films are amorphous when sputtering at a lower RF power of $15 \mathrm{~W}$. It does increase the $\mathrm{N}$ atomic percentage.

Sputtering with $40 \mathrm{~W}$ RF power and $10 \mathrm{mT}$ pressure, XRD spectra revealed weak crystallization at 36.7 beginning to form, however the film eventually becomes amorphous if the nitrogen concentration is lower than $60 \%$, Figure 3 . This is attributed to the intense ion bombardment from the argon gas, causing a re-sputtering at the surface of the thin film. This is also observed in [18].

Comparing the SEM surface images taken of the $\mathrm{GaN}$ films sputtered using $40 \% \mathrm{~N}_{2}$ for $1 \mathrm{hr}$ vs $2 \mathrm{hrs}$, showed small grains $(\sim 15 \mathrm{~nm})$ are visible initially, and over time (2 hrs) the grains become less defined, Figure 4. Additionally, target poisoning is still observed when sputtering at $40 \% \mathrm{~N}_{2}$ or lower. The effect is greatly reduced at low powers and higher pressures. GaN deposited on both silicon and sapphire wafer resulted in thin films close to stoichiometric once the $\mathrm{N}_{2}$ concentration is $60 \%$ or higher.

The characteristics of the films deposited on the sapphire wafer are shown on Table 3.

Table 2. Characteristics of sputtering using various concentration of N2 and argon.

\begin{tabular}{|c|c|c|c|c|c|c|c|c|}
\hline \multirow{2}{*}{$\begin{array}{c}\text { Nitrogen } \\
\text { Gas (\%) }\end{array}$} & \multirow{2}{*}{$\begin{array}{l}\text { Power } \\
\text { (W) }\end{array}$} & \multirow{2}{*}{$\begin{array}{l}\text { Pressure } \\
\qquad(\mathrm{mT})\end{array}$} & \multirow{2}{*}{$\begin{array}{l}\text { Thickness } \\
\text { (nm) }\end{array}$} & \multicolumn{3}{|c|}{ Atomic percentage } & \multirow{2}{*}{$\begin{array}{l}\text { N/Ga } \\
\text { Ratio }\end{array}$} & \multirow{2}{*}{$\begin{array}{l}\text { Time } \\
\text { (hrs.) }\end{array}$} \\
\hline & & & & $\mathrm{Ga}(\%)$ & N (\%) & $\mathrm{O}(\%)$ & & \\
\hline 0 & 40 & 5 & 175.63 & 28.3 & 5.48 & 22.04 & 0.19 & 1 \\
\hline 25 & 40 & 5 & 74.3 & 21.03 & 4.49 & 30.84 & 0.21 & 1 \\
\hline 33 & 40 & 5 & 146.43 & 13.7 & 3.63 & 25.58 & 0.27 & 2 \\
\hline 33 & 40 & 10 & 146 & 35.02 & 7.2 & 45.47 & 0.21 & 2 \\
\hline 33 & 40 & 20 & 29.63 & 7.39 & 2.13 & 14.05 & 0.28 & 2 \\
\hline 33 & 40 & 30 & 16.9 & 3.45 & 1.63 & 7.88 & 0.47 & 2 \\
\hline 33 & 50 & 20 & 37.58 & 10.35 & 2.32 & 18.95 & 0.22 & 2 \\
\hline 33 & 50 & 30 & 18.1 & 5.25 & 1.86 & 10.79 & 0.35 & 2 \\
\hline 40 & 40 & 10 & 35.45 & 8.69 & 2.85 & 16.41 & 0.33 & 1 \\
\hline 40 & 40 & 10 & 64.72 & 8.62 & 3.22 & 17.31 & 0.37 & 2 \\
\hline 60 & 40 & 15 & 15.42 & 6.98 & 3.51 & 14.89 & 0.5 & 1 \\
\hline 60 & 40 & 15 & 34.05 & 8.48 & 3.44 & 16.07 & 0.41 & 2 \\
\hline 60 & 15 & 15 & 7.32 & 2.69 & 2.15 & 6.21 & 0.80 & 3 \\
\hline 100 & 15 & 15 & 3.1 & 1.15 & 2.88 & 5.84 & 2.5 & 3 \\
\hline 100 & 40 & 15 & 22.22 & 4.07 & 2.99 & 8.89 & 0.73 & 2 \\
\hline
\end{tabular}




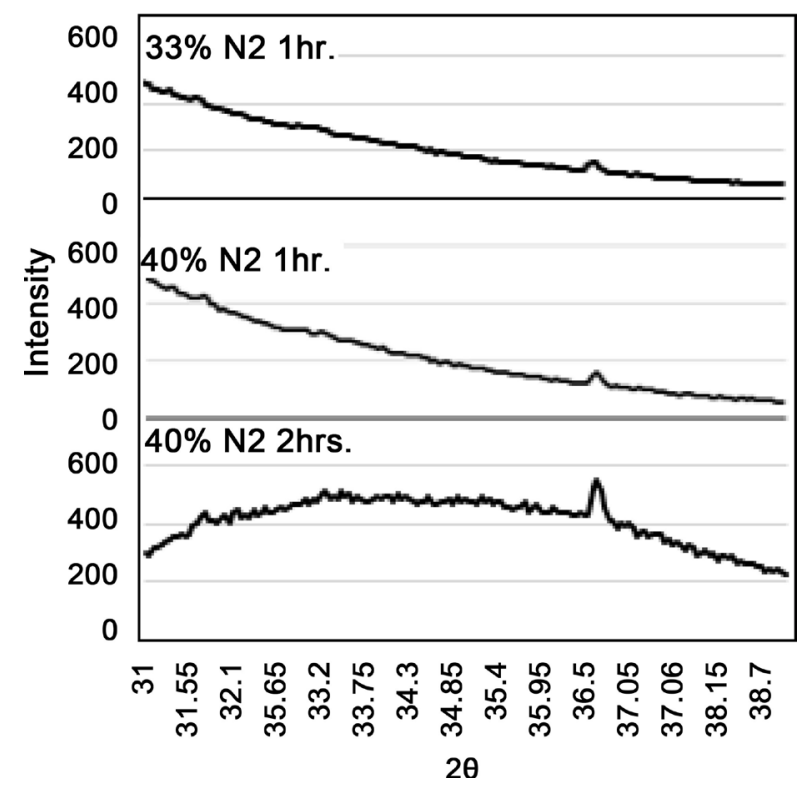

Figure 3. Depositions of 1) $33 \% \mathrm{~N}_{2} 1 \mathrm{hr}$, 2) $40 \% \mathrm{~N}_{2} 1 \mathrm{hr}$ and 3) $40 \% \mathrm{~N}_{2} 2$ hrs.

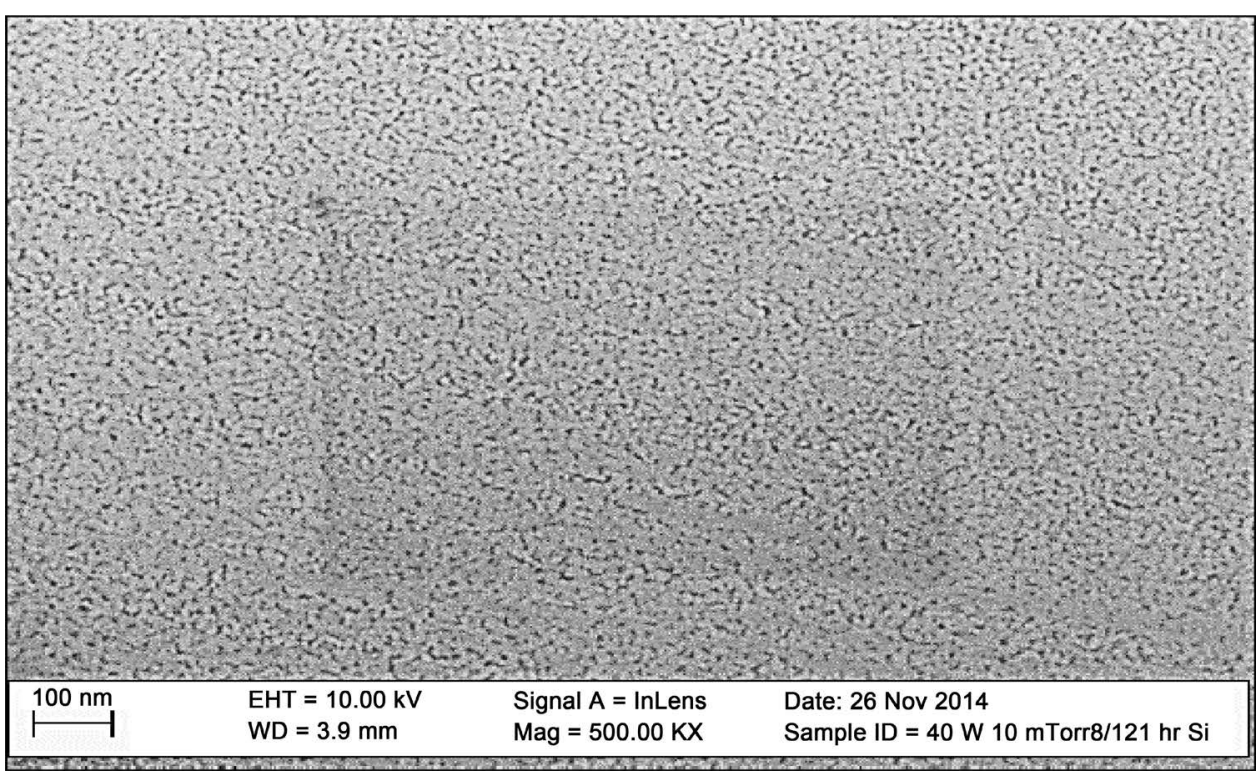

Figure 4. SEM surface image of GaN films with sputtering parameters.

Table 3. Characteristics of sputtering using various concentrations of N2 and argon gas on sapphire wafer.

\begin{tabular}{ccccccccc}
\hline $\begin{array}{c}\text { Nitrogen Gas } \\
(\%)\end{array}$ & $\begin{array}{c}\text { Power } \\
(\mathrm{W})\end{array}$ & $\begin{array}{c}\text { Pressure } \\
(\mathrm{m} T)\end{array}$ & $\begin{array}{c}\text { Thickness } \\
(\mathrm{nm})\end{array}$ & \multicolumn{2}{c}{ Atomic percentage } & $\begin{array}{c}\text { N/Ga } \\
\text { Ratio }\end{array}$ & $\begin{array}{c}\text { Time } \\
(\mathrm{hrs})\end{array}$ \\
\hline 60 & 40 & 15 & 32 & 5.5 & 6.26 & 57.99 & 1.1 & 2 \\
60 & 15 & 15 & 6 & 1.92 & 3.37 & 56.14 & 1.75 & 3 \\
100 & 40 & 15 & 22 & 5.5 & 6.26 & 57.99 & 1.13 & 2 \\
100 & 15 & 15 & 3 & 3.13 & 3.3 & 55.83 & 1.05 & 3 \\
\hline
\end{tabular}


The $15 \mathrm{~W}$ RF power proved to be inefficient due to a reduction in sputtering rate, making it unpractical. In addition, although the N/Ga increased, the films are amorphous. The amorphous state of the film could be due to insufficient time given during sputtering for the film to grow and get passed the nucleation phase.

The biggest factor affecting the depositions is the atomic percentage of oxygen incorporated in the film during deposition. Even though close to stoichiometric films are produced when sputtering with $60 \% \mathrm{~N}_{2}$ and an RF power of $40 \mathrm{~W}$, there is still a high concentration of oxygen.

The incorporation of oxygen is concluded to be from impurities already incorporated into the gas chamber. To reduce the oxygen levels in the films, the substrate temperature is utilized. The effect of the high temperature deposition results in polycrystalline films, with a significant reduction in oxygen. Table 4 shows the characteristics of sputtering under $40 \mathrm{~W} R F$ power and $5 \mathrm{mT}$ pressure using a substrate temperature of $400^{\circ} \mathrm{C}$ or $700^{\circ} \mathrm{C}$. With $400^{\circ} \mathrm{C}$ on the silicon and the sapphire substrates, the oxygen levels are greatly reduced and weak crystallization is observed.

Increasing the substrate temperature to $700^{\circ} \mathrm{C}$ significantly reduces the oxygen and the film is mostly compost of gallium and nitrogen. XRD pattered showed polycrystalline thin film with wurtzite $\mathrm{GaN}$ of mixed orientations (100, 002, 101, 110, and 103) with a preferred orientation of $\mathrm{GaN}$ (002) on both silicon and sapphire, Figure 5. SEM surface images taken of the depositions revealed grain sizes of $40 \mathrm{~nm}-38 \mathrm{~nm}$ grains on silicon and $62 \mathrm{~nm}-39 \mathrm{~nm}$ on sapphire, Figure 6. XPS analysis showed the impurities of oxygen in each of the thin films. The oxygen is only less than $\mathrm{Ga}$ when no $\mathrm{N}_{2}$ is used. Figure 7 shows the effects of temperature on depositions. The oxygen levels have been controlled significantly at elevated temperatures.

One of the major challenges is the target poisoning during the sputtering. When sputtering with pure argon gas and low pressures, target poisoning is greatly observed, Once the pressure is increased to $20 \mathrm{mT}$, the effect begins to be reduced. The introducing of $\mathrm{N}_{2}$, positively affects the conditions of the target.

However, sputtering at $50 \mathrm{~W}$ RF power still creates the effect at low pressures. When sputtering with $40 \mathrm{~W}$ RF power and high pressure of $10 \mathrm{mT}$, the effect is suppressed but not completely reduced. Once the process gas is $60 \%$ or higher $\mathrm{N}_{2}$, sputtering can be done at low or high pressures. The optimized conditions are an RF power of $40 \mathrm{~W}$ or

Table 4. Characteristics of sputtering using different substrate temperatures

\begin{tabular}{cccccccc}
\hline \multicolumn{7}{c}{ Nitrogen Gas 40 W RF power and $5 \mathrm{mT}$ pressure } \\
\hline \multirow{2}{*}{ Wafer } & Temperature & Thickness & \multicolumn{2}{c}{ Atomic percentage } & N/Ga & Time \\
\cline { 2 - 7 } & $\left({ }^{\circ} \mathrm{C}\right)$ & $(\mathrm{nm})$ & $\mathrm{Ga}(\%)$ & $\mathrm{N}(\%)$ & $\mathrm{O}(\%)$ & Ratio & (hours) \\
\hline Silicon & 400 & 40 & 9.7 & 9.28 & 8.77 & 0.96 & 1 \\
Sapphire & 400 & 40 & 8.04 & 7.23 & 47.32 & 0.90 & 1 \\
Silicon & 700 & 300 & 48.09 & 36.85 & 6.28 & 0.77 & 10 \\
Sapphire & 700 & 300 & 51.35 & 37.6 & 6.48 & 0.73 & 10 \\
\hline
\end{tabular}




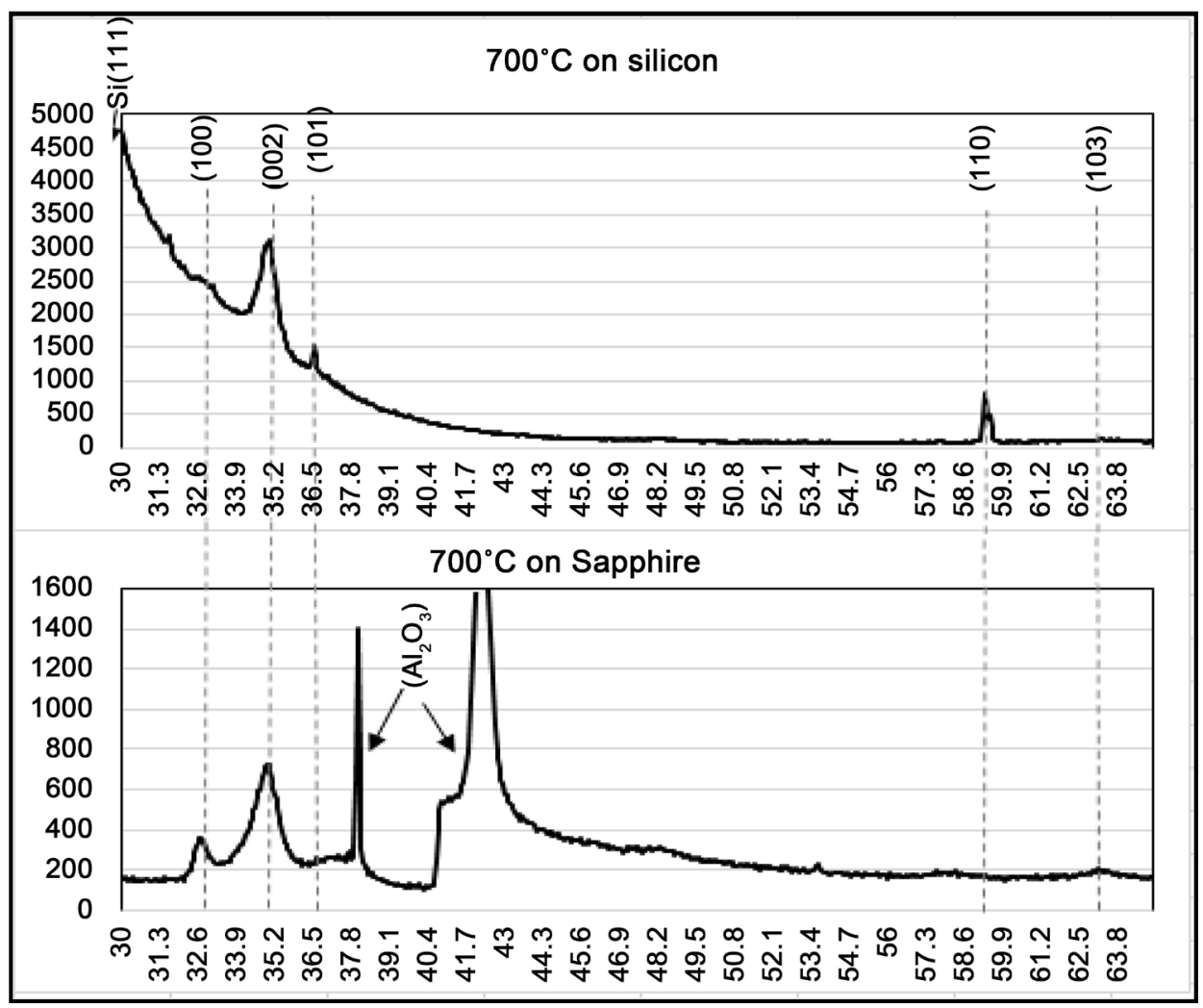

Figure 5. X-ray diffraction patters of GaN films; $40 \mathrm{RF}$ power, $5 \mathrm{mT}$ pressure and $700^{\circ} \mathrm{C}$ temperature.

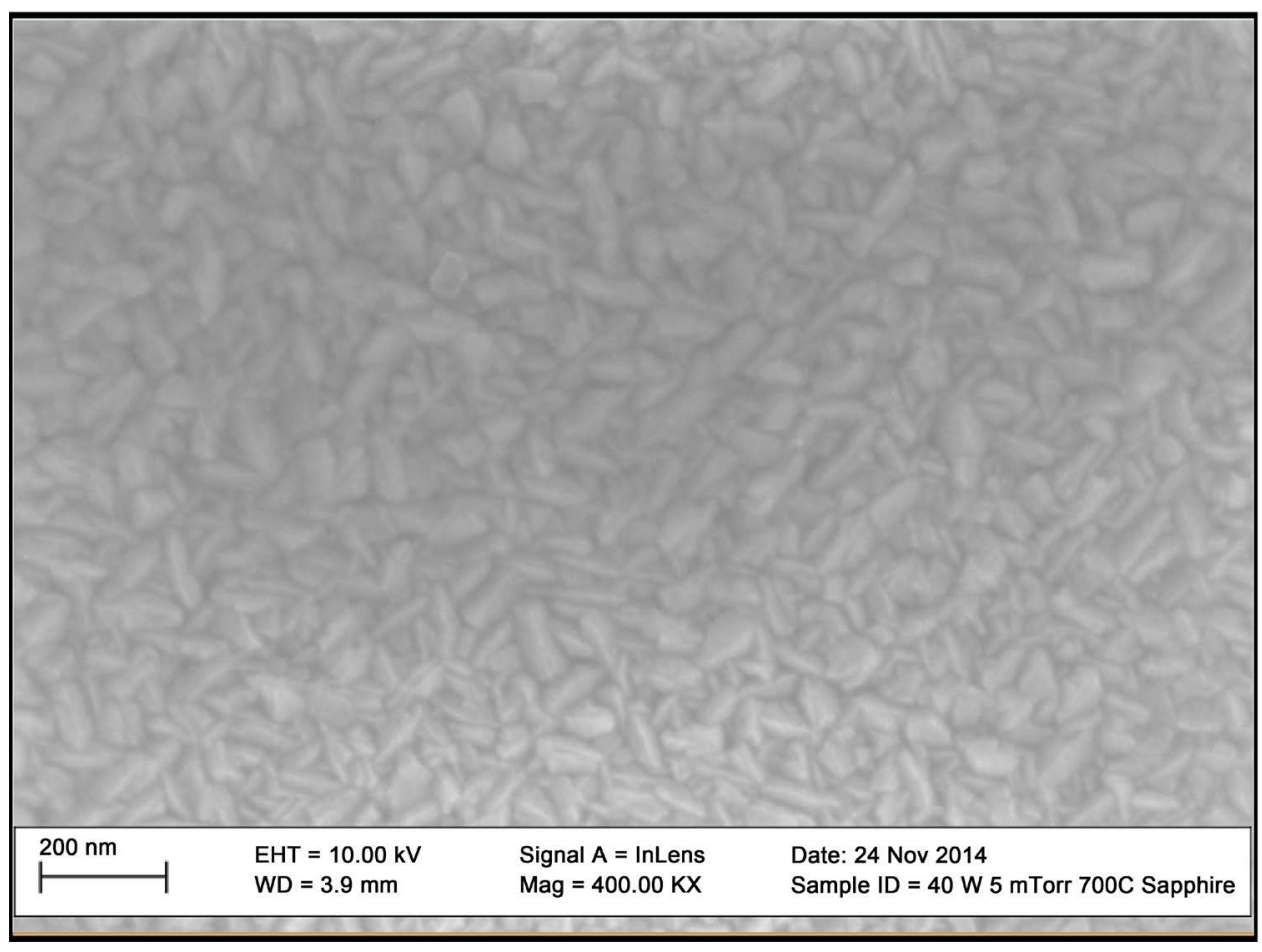

Figure 6. SEM surface images of sputtered GaN thin films. $40 \mathrm{RF}$ power and $5 \mathrm{mT}$ pressure using $700^{\circ} \mathrm{C}$ substrate temperature, grain sizes of $62 \mathrm{~nm}-39 \mathrm{~nm}$ on sapphire wafer. 


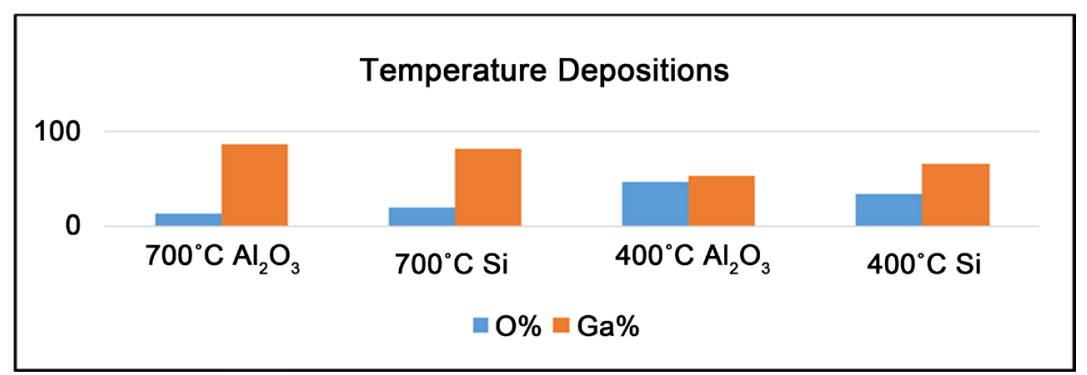

Figure 7. Bar graphs depicting the atomic percentage of oxygen vs gallium; Atomic percentage of oxygen vs gallium using temperatures of $400^{\circ} \mathrm{C}$ and $700^{\circ} \mathrm{C}$ on $\mathrm{Si}$ and $\mathrm{Al}_{2} \mathrm{O}_{3}$ wafers.

Table 5. Characteristics of sputtering using different substrate temperatures.

\begin{tabular}{cccccccc}
\hline $\begin{array}{c}\text { Power } \\
(\mathrm{W})\end{array}$ & $\begin{array}{c}\text { Pressure } \\
(\mathrm{mT})\end{array}$ & $\begin{array}{c}\text { Thickness } \\
(\mathrm{nm})\end{array}$ & Ga \% & N \% & O \% & $\begin{array}{c}\text { N/Ga } \\
\text { Ratio }\end{array}$ & $\begin{array}{c}\text { Time } \\
\text { (hours) }\end{array}$ \\
\hline 50 & 4 & 99.53 & 33.7 & 11.08 & 34.07 & 0.33 & 1 \\
40 & 4 & 78.1 & 6.42 & 1.15 & & 0.18 & 1 \\
40 & 5 & 72.62 & 14.6 & 4.1 & & 0.28 & 1 \\
40 & 10 & 41.2 & 11.4 & 4.62 & 20.21 & 0.40 & 1 \\
40 & 10 & 43.4 & 11.9 & 5.03 & 20.41 & 0.42 & 1 \\
40 & 5 & 41.19 & 25.4 & 14.41 & 26.58 & 0.56 & 2 \\
\hline
\end{tabular}

below with a pressure between $10 \mathrm{mT}$ and $20 \mathrm{mT}$. Sputtering at a low pressure $(5 \mathrm{mT})$ is possible once these conditions are met, however some target poisoning is still observed. However, this effect is minimal and sputtering can be carried out without affecting the deposition. A similar phenomenon is observed in [18], were target poisoning is observed at the surface of the substrate where a re-sputtering of the deposited film is observed when sputtering at high powers and low pressures, leaving the film $\mathrm{N}$ deficient. This is likely due to inadequate sputtering conditions that cause re-sputtering to happen at the surface, resulting in the surface of the target decomposing and losing nitrogen.

Table 5 shows the characteristics of the target poisoning on the ratio of the N/Ga. These depositions are done sequentially starting from the top down. In the first depositions, sputtering at low pressures $(4-5 \mathrm{mT})$, the target is mostly black and the N/Ga ratios are really low. After sputtering at adequate conditions of $40 \mathrm{~W}$ RF power and 10 $\mathrm{mT}$ pressure, the target is now mostly clean, and the deposition done after at $40 \mathrm{~W} \mathrm{RF}$ power and $5 \mathrm{mT}$ pressure had an increase in the N/Ga ratio. This proves that the cleanliness of the target is important as it has a great effect on the stoichiometry.

\section{Conclusion}

In this study, a middle-frequency magnetron-sputtering method is adopted to deposit GaN on Si (111), Sapphire and glass substrates. Experimental results revealed that polycrystalline $\mathrm{GaN}$ thin film with a hexagonal $\mathrm{GaN}$ wurtzite structure is grown on silicon and sapphire wafers. Glass substrate is not suitable for GaN. In addition, oxygen 
impurities incorporated during the deposition are shown to be reduced by using temperature depositions. The samples are made with various parameters. The deposition rate of the films is observed. The study showed that the high quality crystal of the GaN thin films depend strongly on the low power $(\sim 40 \mathrm{~W})$, high gas pressure $(\sim 15 \mathrm{mT})$ and annealing effects. This is comparable as in [19] where films deposited on both single crystal and amorphous substrates had the same orientation due to RF magnetron sputtering being almost free of tangential growth. Best deposition parameters are achieved at low powers and high pressures, with the addition of $60 \% \mathrm{~N}_{2}$ gas or higher, enhancing the incorporation of nitrogen on to the thin film, and increasing the average N/Ga ratio to achieve stoichiometry. Otherwise, the argon ions have enough energy to re-sputter at the surface of the thin film, leaving them nitrogen deficient. Additionally, target poisoning is created under inadequate sputtering conditions and decreases as the nitrogen gas percentage increases.

\section{Acknowledgements}

This project is supported in part by the National Science Foundation (NSF) under Grant No. 1229523, and by the US Army Research Office W911NF-14-1-0100.

\section{References}

[1] Culbertson, L. (2014) Wide Bandgap Semiconductors Go Beyond Silicon in Power, RF, LED Lighting, and Optoelectronics. Mouser Electronics. http://www.mouser.com/applications/

[2] Callister, W.D. (2007) Materials Science and Engineering: An Introduction. 7th Edition, John Wiley \& Sons, New York.

[3] Shur, M. and Davis, R.F. (2004) GaN-Based Materials and Devices: Growth, Fabrication, Characterization and Performance. World Scientific, Singapore.

http://dx.doi.org/10.1142/5539

[4] Fan, R., Pearton, S.J., Kang, B.S. and Chu, B.H. (2011) AlGaN/GaN High Electron Mobility Transistor Based Sensors for Bio-Applications. In: Serra, P.A., Ed., Biosensors for Health, Environment and Biosecurity, InTech.

[5] Kang, B.S., Wang, H.T., Ren, F. and Pearton, S.J. (2008) Journal of Applied Physics, 104, Article ID: 031101.

[6] Pearton, S.J., Abernathy, C.R. and Ren, F. (2006) Gallium Nitride Processing for Electronics, Sensors and Spintronics. Springer, London.

[7] Ohring, M. (2002) Materials Science of Thin Films: Deposition and Structure. 2nd Edition, Academic, San Diego.

[8] Chandra, S., Bhatt, V. and Singh, R. (2009) Sadhana, 34, 543-556.

http://dx.doi.org/10.1007/s12046-009-0032-y

[9] Bhatt, V., Chandra, S., Kumar, S. and Rauthan, C.M. (2007) Indian Journal of Pure and Applied Physics, 45, 377-381.

[10] Wang, C.-W., Soong, B.-S., Chen, J.-Y., Chen, C.-L. and Su, Y.-K. (2000) Journal of Applied Physics, 88, 6355-6358. http://dx.doi.org/10.1063/1.1324700

[11] Kim, H.W. and Kim, N.H. (2004) Applied Surface Science, 236, 192-197. 
[12] Kim, J.H., Davidson, M.R. and Holloway, P.H. (2003) Applied Physics Letters, 83, 47464748. http://dx.doi.org/10.1063/1.1627471

[13] Kim, J.H. and Cho, K.Y. (2013) Journal of the Korean Physical Society, 62, 619-622. http://dx.doi.org/10.3938/jkps.62.619

[14] Devaraju, G., Pathak, P.A., Rao, N.S., Saikiran, V., Rao, S.V.S. and Titov, A.I. (2012) Radiation Effects \& Defects in Solids, 167, 659-665. http://dx.doi.org/10.1080/10420150.2012.688204

[15] Miyazaki, T., Takada, K. and Adachi, S. (2005) Journal of Applied Physics, 97, Article ID: 093516.

[16] Miyazaki, T., Fujimaki, T. and Sadao, A. (2001) Journal of Applied Physics, 89, 8316-8320. http://dx.doi.org/10.1063/1.1368393

[17] Zou, C.W., Yin, M.L., Li, M., Liu, C.S., Guo, L.P. and Fu, D.J. (2008) Thin Solid Films, 517, 670-673. http://dx.doi.org/10.1016/j.tsf.2008.07.038

[18] Maruyama, T. and Miyake, H. (2006) Journal of Vacuum Science and Technology, 24, 1096. http://dx.doi.org/10.1116/1.2208988

[19] Blaut-Blachev, A.N. (2000) Semiconductors, 35, 688-689. http://dx.doi.org/10.1134/1.1379405

[20] Horng, R.H., Wuu, D.S., Wei, S.C., Chan, S.H. and Kung, C.Y. (1999) Thin Solid Films, 343-344, 642-645. for you:

Accepting pre-submission inquiries through Email, Facebook, LinkedIn, Twitter, etc. A wide selection of journals (inclusive of 9 subjects, more than 200 journals)

Providing 24-hour high-quality service

User-friendly online submission system

Fair and swift peer-review system

Efficient typesetting and proofreading procedure

Display of the result of downloads and visits, as well as the number of cited articles

Maximum dissemination of your research work

Submit your manuscript at: http://papersubmission.scirp.org/

Or contact jmp@scirp.org 